\title{
CONTRIBUIÇÕES DA INICIAÇÃO CIENTÍFICA NOS CURSOS TÉCNICOS DE NÍVEL MÉDIO DO INSTITUTO FEDERAL DO ACRE
}

\author{
Raphaela Bomfim de Oliveira; José Marlo Araújo de Azevedo; Hellen Sandra Freires da Silva \\ Azêvedo; Mirna Suelby Martins da Rocha \\ Instituto Federal do Acre, Campus Cruzeiro do Sul \\ DOI: 10.15628/rbept.2019.7741 \\ Artigo submetido em set/2018 e aceito em ago./2019
}

\begin{abstract}
RESUMO
É perceptível a relevância da iniciação científica na formação dos estudantes, uma vez que além de aproximarem os alunos da pesquisa, proporciona ricas experiências acadêmicas e de vida. $O$ objetivo deste trabalho foi investigar a perspectiva de alunos, docentes e gestores sobre os impactos da iniciação científica na formação dos alunos dos cursos técnicos de nível médio do Instituto Federal do Acre - Campus Cruzeiro do Sul. A pesquisa classifica-se como explicativa, sendo utilizado o método quali-quantitativo, em que foram aplicados questionários semiestruturados a seis egressos que foram bolsistas do Programa Institucional de Bolsa de Iniciação Científica na modalidade Júnior (PIBIC Jr), a 14 docentes e três integrantes da equipe gestora. Os resultados evidenciam que os alunos compreendem a importância da iniciação científica para a sua formação e que, além de aproximá-los da ciência, habilidades como escrita, leitura, trabalho em equipe e expressão oral são melhoradas. A maioria dos docentes também ratifica essa importância da iniciação científica nos cursos técnicos, no entanto relatam que há limitações às atividades de pesquisa, sendo a infraestrutura inadequada e a falta de tempo, apontadas pela maioria dos entrevistados. A equipe gestora também declara ser importante a iniciação científica, concorda haver fatores limitantes à pesquisa no campus e citaram seus esforços na busca da minimização e/ou resolução destas problemáticas.
\end{abstract}

Palavras-Chave: Ciência. Educação Profissional. PIBIC Júnior.

\section{CONTRIBUTIONS OF SCIENTIFIC INITIATION IN THE TECHNICAL COURSES OF MEDIUM LEVEL OF THE FEDERAL INSTITUTE OF ACRE}

\begin{abstract}
It is perceptible the relevance of scientific initiation to formation of students, once that beyond approximate them of research, provides rich academic and life experiences. In this sense, the aim of this work was investigate the perspective of students, teachers and managers about the impacts of scientific initiation in the formation of students of technical courses of middle level in the Federal Institute of Acre - Campus Cruzeiro do Sul. The research is classified like explicative, being used the quail-quantitative method, on what semi-structured questionnaires were applied to six students that had scientific initiation scholarship, teachers 14 and three members of manager team. The results show that the students understand the importance of scientific initiation to their formation and that, besides approximate them of science, abilities like write, read, team work and oral expression are improved. Most of teachers also believe in the importance of scientific initiation on technical courses; however, they report that there are limitations to research activities, being the inadequate infrastructure and the lack of time pointed by majority of interviewed. Managers team also report that scientific initiation is important and agree that there are limiting factors to research in the campus; however, they mention your efforts to look for the minimization and/or resolution of these problematic.
\end{abstract}

Keywords: Science. Professional Education. Scientific Research 


\section{INTRODUÇÃO}

A pesquisa científica compõe o tripé ensino, pesquisa e extensão, que define as instituições de educação superior (IES). É visível, porém, que nos últimos anos a pesquisa tem se configurado como item de desenvolvimento não apenas na graduação, mas também nos cursos de formação média e técnica. Embora o termo iniciação científica (IC) seja rapidamente associado a alunos de cursos superiores, os estudantes da educação profissional técnica de nível médio também são atendidos por este programa - apesar da pouca visibilidade dada à pesquisa para este público.

De modo geral, a pesquisa auxilia na construção da autonomia intelectual do estudante, devendo estar intimamente relacionada ao ensino e presente em todos os tipos de oferta, seja no nível básico ou no superior. Necessariamente, as estratégias e as metodologias utilizadas devem se adequar à faixa etária e ao nível de amadurecimento intelectual dos educandos e devem ser capazes de instigar o sentido de curiosidade do alunado, orientando-os ao estudo e à busca de soluções para as problemáticas do cotidiano (BARACHO et al., 2006; MOURA, 2007).

Visando integrar os alunos, de forma abrangente, à pesquisa científica, em 1987, o Conselho Nacional de Desenvolvimento Científico e Tecnológico (CNPq) criou o Programa Institucional de Iniciação Científica (ALENCASTRE et al., 1996). Assim, desde sua criação, é perceptível a importância da IC na formação dos estudantes, uma vez que além de aproximá-los da ciência, proporciona ricas experiências com os orientadores, incluindo o aperfeiçoamento da criticidade, o desenvolvimento de habilidades instrumentais necessárias para o método científico, a participação em eventos científicos entre outros, que ampliam a aprendizagem dos estudantes e os deixam mais confiantes (ERDMANN et al., 2010).

Tais atitudes quando despertadas logo nas primeiras fases escolares, corroboram para que, nos níveis de ensino subsequentes, os discentes possam elaborar questões investigativas no campo mais formal, seja na pesquisa de base ou na aplicada (BARACHO et al., 2006; MOURA, 2007).

Há pouco mais de uma década, apesar do número de bolsistas de IC já ser considerável, o número de artigos sobre a temática não era numerosa (QUEIROZ e ALMEIDA, 2004) e ainda hoje percebe-se a incipiência de trabalhos na área, existindo mais artigos que versam sobre a sua importância na graduação (PEREIRA et al., 1999; BALLARIN e TOLDRÁ, 2001; BRIDI e PEREIRA, 2004; CARDOSO et al., 2005; OLIVEIRA et al., 2008; PALMEIRA e RODRIGUEZ, 2008; BASTOS et al., 2010; ERDMANN et al., 2010), sendo mínima a abordagem desse tema em relação aos cursos técnicos de nível médio.

Em 2011, a Pró-Reitoria de Pesquisa, Inovação e Pós-Graduação do Instituto Federal de Educação, Ciência e Tecnologia do Acre (IFAC) em parceria 
com o CNPq, com o objetivo de aproximar os alunos do mundo da pesquisa e estimular o avanço científico, realizou uma Mostra de Pesquisa e Inovação na Educação Profissional, em que selecionou bolsistas, de cursos técnicos e superiores, para desenvolver trabalhos científicos. Os alunos selecionados receberiam uma bolsa no valor de $R \$ 100,00$ e apresentariam a pesquisa no evento (IFAC, 2011).

Ainda no mesmo ano, o IFAC divulgou edital de Programa de Iniciação Científica, no entanto, voltado apenas para alunos dos cursos superiores. Já em 2012, o edital de Iniciação Científica contemplava os alunos dos cursos técnicos, na modalidade Júnior e, a partir de então, várias outras seleções ocorreram.

Portanto, considerando a importância da Iniciação Cientifica na vida dos estudantes e que o IFAC/Campus Cruzeiro do Sul teve alunos de cursos técnicos como bolsistas deste programa, surgiu a necessidade de avaliar o seu impacto na formação dos educandos.

Outrossim, tanto o quadro de docentes do Instituto Federal do Acre/Campus Cruzeiro do Sul quanto a quantidade de alunos matriculados cresceram bastante desde seu início, no ano de 2010, entretanto o número de bolsistas de iniciação científica ainda é escasso - como observou-se nos últimos editais - sendo possível a existência de fatores, institucionais ou não, que limitam as ações de pesquisa.

Além disso, de acordo com Tenório e Beraldi (2010), a região Sudeste do Brasil é onde se concentra o maior número de instituições de ensino superior e, por isso, é a maior em distribuição de recursos para a pesquisa e em quantidade de bolsistas de IC, enquanto a região Norte é a que menos recebe verba para investimentos na pesquisa, sendo aquém do desejado (ANTUNES et al., 2006). Da mesma forma, também são escassas as investigações acerca da IC no Norte do país, importando estudar o seu desenvolvimento em instituições da região Amazônica.

Desse modo, objetivou-se analisar as contribuições que os programas de Iniciação Científica têm na vida dos estudantes de cursos técnicos de nível médio do IFAC, Campus Cruzeiro do Sul, diagnosticando também possíveis falhas na execução de programas de IC na instituição e a perspectiva docente e da equipe gestora sobre a temática.

\section{CONTRIBUIÇÃO DA PESQUISA PARA O DESENVOLVIMENTO DA SOCIEDADE E PARA A FORMAÇÃO DO ALUNO}

A primeira finalidade dos Institutos Federais de Educação, Ciência e Tecnologia descrita na Lei $n^{0}$ 11.892, de 29 de dezembro de 2008, é a de "ofertar educação profissional e tecnológica, em todos os seus níveis e modalidades, formando e qualificando cidadãos com vistas a atuação profissional nos diversos setores da economia, com ênfase no desenvolvimento socioeconômico local, 
regional e nacional" (BRASIL, 2008). Machado et al. (2009) entendem que as mudanças na sociedade só ocorrem com o surgimento de novos desafios e é nesse momento que a ciência exerce um papel fundamental, descobrindo a solução para eles. Destarte, não existe desenvolvimento social e econômico sem uma base científica e tecnológica produtiva, que tornem os cidadãos construtores e renovadores de conhecimentos, capazes de atuar efetivamente na sociedade em que está inserido (FAVA-DE-MORAES e FAVA, 2000; AMORIM, 2011).

Os Institutos Federais são fundamentais no processo de construção do conhecimento científico e na produção de inovações tecnológicas, estando incluídas em suas finalidades o desenvolvimento de programas de extensão, bem como de divulgação científica e tecnológica e o incentivo à pesquisa aplicada e ao desenvolvimento científico e tecnológico (BRASIL, 2008). Para Silva (2009), a pesquisa científica nestas instituições deve ser fundamentada nas demandas locais, devendo ser estimulada em todos os níveis de ensino e não apenas na pós-graduação.

Há alguns anos, porém, o número de profissionais que atuavam na produção de conhecimentos científicos e tecnológicos era incipiente (FAVA-DEMORAES e FAVA, 2000) e ainda hoje, mesmo com os avanços científicos e tecnológicos, a quantidade de pesquisadores é insuficiente, sendo imprescindível qualificar recursos humanos para que esse número seja ampliado (AMORIM, 2011). Consequentemente, visando despertar a vocação para ciência e descobrir novos talentos, foi iniciada, pelo Conselho Nacional de Desenvolvimento Científico e Tecnológico (CNPq), a proposta da iniciação científica aos alunos de graduação (Erdmann e Pagliuca, 2007), também já estendida aos alunos do ensino médio, sendo esta citada como necessária na construção do currículo, nas Diretrizes Curriculares Nacionais para a Educação Profissional Técnica de Nível Médio (BRASIL, 2012).

O PIBIC Júnior foi normatizado em 2006 pelo CNPq, cuja finalidade é estimular 0 interesse pela ciência e incentivar possíveis talentos entre os estudantes do ensino básico (CNPq, 2006). Na pesquisa de Hartmann e Zimmermann (2009), foi constatado que professores do ensino médio buscavam desenvolver trabalhos de iniciação científica, inserindo-os no mundo da ciência através de levantamento de problemas a serem resolvidos através de uma pesquisa e esta atividade favorecia o desenvolvimento dos estudantes.

De acordo com Queiroz e Almeida (2004), além de inserir os alunos nos projetos de pesquisa e qualificá-los para compreender e "fazer ciência", a iniciação científica também aperfeiçoa o indivíduo. Conforme a pesquisa realizada por Bridi (2010) na Universidade Estadual de Campinas (Unicamp), a maioria dos entrevistados concorda que a iniciação científica contribui tanto para a formação específica quanto para a formação ampla e cultural do estudante, abrangendo aspectos intelectuais, culturais e morais.

Campos et al. (2009), em uma pesquisa relacionada ao ensino superior, chegaram à conclusão de que os alunos reconhecem a importância da pesquisa para sua formação profissional, já que esta tende a ampliar o conhecimento nas 
disciplinas e conteúdo específicos, além de proporcionar autorreflexão e aperfeiçoamento na habilidade de gestão e organização no trabalho.

Semelhantemente, a iniciação científica no ensino médio proporciona aos alunos o desenvolvimento de "sua capacidade de explicar, justificar, predizer, estimar, interpretar, fazer julgamentos e inferir", sendo atributos promissores para a sua formação (HARTMANN e ZIMMERMANN, 2000).

Ainda assim, Campos et al. (2009) acreditam que os discentes são pouco estimulados a participarem dos programas de iniciação científica - o que pode ocorrer devido a falhas no sistema educacional.

Consoante Escott et al. (2013), muitas instituições que originaram os institutos federais já possuíam uma cultura enraizada, enquanto os institutos federais criados após a Lei 11.982 de 19/12/2008, possuem fragilidades, sendo que essas características em ambos os casos podem dificultar a realização de pesquisa. Além disso, a captação de recursos externos em institutos que não possuem programas de pós-graduação stricto sensu é bem mais restrita, já que os editais de apoio à pesquisa das empresas de fomento privilegiam os estabelecimentos de ensino mais antigos e que já possuem cursos de mestrado e/ou doutorado.

Outra barreira para a pesquisa, conforme os autores acima citados, é o incentivo à interiorização da educação pública no âmbito federal, que permite a criação de um elevado número de campi em diversas localidades, em que muitos cidadãos, motivados pelo desejo de ingressar no serviço público, prestam concurso para os municípios mais afastados e, muitas vezes, não estabelecem vínculo com a cidade, adquirindo pouco conhecimento sobre a realidade da região - o que é um entrave para pesquisa aplicada focada no desenvolvimento regional. Dessa forma, buscam remoção/redistribuição para outro campus, não realizam pesquisa e nem incentivam os discentes a fazê-la, sendo possível a existência de tais obstáculos no IFAC.

Desta maneira, gerir a pesquisa numa instituição multicampi, pluricurricular e com diferentes modalidades de ensino é um desafio, ficando a gestão condicionada a superar as barreiras existentes, motivando professores e alunos a construírem conhecimento científico, visando o desenvolvimento local.

\section{METODOLOGIA}

Objetivando-se analisar as contribuições dos programas de Iniciação Científica na vida dos estudantes de cursos técnicos de nível médio do IFAC, foi utilizado o método quali-quantitativo. Optou-se, ainda, por uma pesquisa explicativa, pois de acordo com Gil (2008) é o tipo "que mais aprofunda o conhecimento da realidade, porque explica a razão, o porquê das coisas".

Inicialmente, foi realizado um levantamento dos alunos dos cursos técnicos de nível médio que foram bolsistas de iniciação científica junto à 
Coordenação de Registro Escolar e à Coordenação de Pesquisa e Inovação do Instituto Federal do Acre/Campus Cruzeiro do Sul. Destes, foram levantadas informações pertinentes ao trabalho, bem como os dados de telefone e endereço. Dos nove egressos que foram bolsistas de Iniciação Científica Júnior, incluindo-se um bolsista da Mostra de Pesquisa e Inovação, contatou-se seis para a explicação do objetivo do estudo, sensibilizando-os a participarem da investigação, efetuando-se, em seguida, a entrega dos questionários semiestruturados. Dos egressos entrevistados, três foram alunos do curso Técnico Integrado ao Ensino Médio em Agropecuária, dois, do curso Técnico Subsequente em Agropecuária e um do curso Técnico Subsequente em Controle Ambiental. O roteiro do questionário buscou, através de perguntas fechadas e abertas, conhecer os motivos que os fizeram participar do programa de iniciação científica e qual a importância para sua formação.

Também foi enviado um questionário específico a 31 docentes dos 54 que compõem o quadro efetivo do IFAC/Campus Cruzeiro do Sul, inclusive os que estavam afastados ou foram removidos há pouco tempo. Ressalta-se que alguns dos professores da instituição atuam majoritariamente nos cursos superiores, dessa forma, preferiu-se entrevistar docentes das áreas mais específicas dos cursos técnicos. Apenas 14 professores responderam o questionário, em que foi identificada a sua visão sobre a importância da Iniciação Científica para os estudantes, bem como possíveis problemas que interfiram nas atividades de pesquisa da instituição.

Além disso, o Diretor Geral, o Diretor de Administração e o Coordenador de Pesquisa foram entrevistados, com a finalidade de se identificar as suas percepções sobre a temática e ações de incentivo à pesquisa na instituição.

Cada participante assinou o termo de Consentimento Livre e Esclarecido, concordando em participar da análise de maneira voluntária e sem ônus aos pesquisadores, consciente de que as informações serão utilizadas somente dentro da pesquisa.

Posteriormente, as informações coletadas foram transcritas para uma planilha no Excel para geração de dados estatísticos.

\section{RESULTADOS E DISCUSSOES}

\subsection{A INICIAÇÃO CIENTÍFICA NA VISÃO DOS ALUNOS QUE PARTICIPARAM DO PROGRAMA}

Quando os alunos que participaram de IC foram questionados sobre o seu entendimento a respeito do programa, $100 \%$ afirmaram ser uma atividade que ensina a fazer e desenvolver projetos de pesquisa científica. Para Bastos et al. (2010), é fundamental que os acadêmicos sejam estimulados a participar de IC para que, dessa forma, envolvam-se nas questões relacionadas ao desenvolvimento científico no país. Acreditamos também que esta ideia é válida 
aos alunos da educação profissional técnica de nível médio. Além disso, para um dos entrevistados, a IC "auxilia na aprendizagem do curso" e outro complementa que "é importante para sua formação profissional porque une experiência acadêmica e área profissional e também a diversas áreas do conhecimento". Ainda outro destacou que a IC "aperfeiçoa o caráter e o entendimento dos alunos" e que é uma importante oportunidade de interação com os professores e pesquisadores, auxiliando-o a conhecer o mundo de uma forma diferenciada. Outro participante também destacou a importância do vínculo estabelecido entre o aluno e o professor.

De acordo com Fonseca (2012), a IC contribui para desenvolver no aluno a sua autonomia intelectual e, devido ao caráter interdisciplinar do programa, há o diálogo com vários campos do saber, proporcionando uma formação mais ampla, tornando o indivíduo mais aberto, flexível, democrático e crítico. Além disso, o autor destaca que há uma complexa relação de ensino e aprendizagem entre os professores e discentes envolvidos, ambos engajados na descoberta e na produção de conhecimentos de forma colaborativa - o que é positivo para os participantes desse processo.

Os entrevistados alegaram que a IC melhorou a sua forma de se expressar oralmente e na escrita, o trabalho em equipe e a leitura, mostrando que o programa, além de estimular cientificamente o aluno, desenvolve capacidades diferenciadas nas expressões escrita e oral e nas habilidades manuais. Ajuda ainda a perder o medo e o pânico diante do novo e a ter mais facilidade ao falar em público, além de possuírem um treinamento mais coletivo e com espírito de equipe (FAVA-DE-MORAES e FAVA, 2000).

Como destacado pelos entrevistados, o vínculo estabelecido entre 0 docente e aluno é notável, ressaltando-se que os docentes exercem grande influência no despertar científico dos alunos, pois $50 \%$ dos entrevistados souberam da existência do programa através dos professores e quando questionados sobre o que os motivaram a participar da IC, $50 \%$ responderam que foi devido ao convite de um docente. Nas atividades de pesquisa, a relação alunoorientador é determinante, pois na perspectiva de Souza e Marques (2011) na graduação, desde que seja construtiva, ela pode resultar em trabalhos que sistematizem e consolidem o conhecimento científico em determinada área, no entanto, quando há rupturas nos relacionamentos e os envolvidos renunciam às suas funções, é provável que haja uma influência negativa no processo de construção e na qualidade das atividades desenvolvidas. O mesmo pensamento pode ser aplicado aos alunos da Iniciação Científica Júnior.

Apesar de o programa oferecer auxílio financeiro para os discentes participantes, nenhum aluno atribuiu a este fator o motivo de se inscrever na IC. $\mathrm{Na}$ pesquisa de Souza e Marques (2011), apenas 26\% dos entrevistados decidiram participar do programa devido à remuneração, sendo outros os fatores motivacionais apontados, como o seu caráter científico e o enriquecimento do currículo. Não obstante, segundo os autores, esta remuneração é essencial para a 
permanência nas atividades de pesquisa, já que ajuda em sua manutenção e permite maior dedicação ao programa.

Quando perguntados se a IC influenciou na sua formação técnica, $100 \%$ responderam "sim, bastante" e quando questionados se a IC influenciou na descoberta de sua vocação profissional, a maioria respondeu que sim (Figura 1).

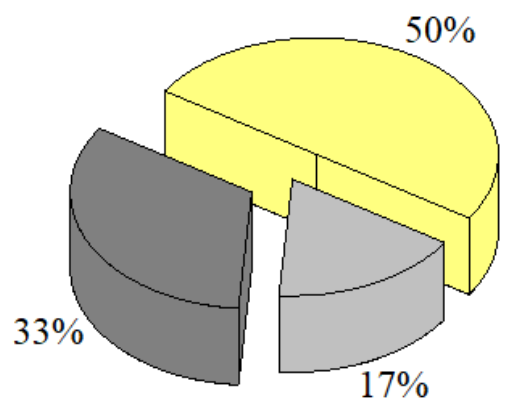

$\square$ Não influenciou

Sim, bastante

Sim, um pouco

Figura 1. Influência da Iniciação científica na escolha profissional.

Ressalta-se, ainda, que $50 \%$ estão cursando nível superior em área relacionada ao curso técnico que concluíram (Figura 2). Martins (2012) destaca que há a expectativa de que a IC no ensino médio propicie o prosseguimento aos estudos e ofereça um encaminhamento profissional ao participante.

Desempregado

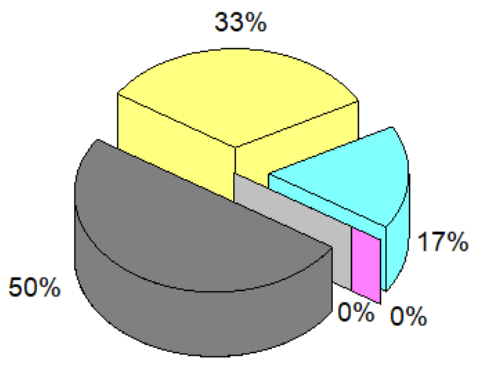

Cursando Graduação na área Curso técnico

Cursando graduação área não relacionada ao curso técnico

Trabalhando na área de formação

Trabalhando em área diferente da formação

Figura 2. Atual situação dos alunos que foram bolsistas de iniciação científica no ensino médio integrado em agropecuária.

Os participantes também foram questionados sobre a sua produção científica e $33 \%$ afirmaram ter publicado os resultados da pesquisa em revista científica e 50\% participaram de eventos científicos. Lacerda et al. (2008) enfatizam que os eventos científicos são essenciais, pois proporcionam a busca e aquisição de novos conhecimentos, assim como são fundamentais no processo da 
comunicação científica, tornando mais rápida a disseminação dos saberes produzidos. Os autores ainda relataram, através do resultado de sua pesquisa, que a maioria dos estudantes percebe a importância destes eventos e que os professores são os principais motivadores da inserção dos discentes nestes ambientes. Além disso, nestes encontros há a troca de experiências que muito beneficiam os participantes através do enriquecimento de seus conhecimentos, havendo também a ampliação de sua visão sobre as diversas áreas de atuação.

Desse modo, o envolvimento dos discentes nas atividades de pesquisa é importante e influencia positivamente sua formação, não apenas despertando a vocação científica, mas também proporcionando a melhora de habilidades diversas.

\subsection{O DOCENTE, A PESQUISA E A INICIAÇÃO CIENTÍFICA}

No contexto do estudo analisado, os professores são fator motivacional para a inserção dos alunos no mundo da pesquisa, pois, uma vez integrando-os em seus projetos, ensina-os a fazer ciência, a buscar soluções para as problemáticas e a enxergar a instituição como meio de transformação de sua região. Na visão de Goulart (2004, p. 68), o docente precisa superar a visão de ser apenas ministrante de aulas, devendo se comportar como "o orientador de um processo de produção do conhecimento" e entregar-se às atividades de pesquisa. E mesmo que o autor se refira a docentes dos cursos de graduação, a ideia deve ser também direcionada aos professores dos cursos técnicos de nível médio. Todavia, muitos docentes ainda não têm esta postura devido a fatores diversos que os desmotivam.

Na presente pesquisa, dos 14 docentes entrevistados, nove são mestres, seguido de três graduados, um especialista e um doutor. Destes, apenas 50\% fazem parte de grupos de pesquisa da instituição. Mocelin (2009) define grupo de pesquisa como a reunião de pesquisadores à volta de projetos, que além de proporcionar a formação de alianças e a combinação de forças para a obtenção de recursos, consolida a comunidade científica. É onde "há envolvimento profissional e permanente com atividades de pesquisa" (DGPB/CNPq, 2015), sendo importante a participação dos docentes nestas equipes.

Quando perguntados se a instituição os incentiva a serem pesquisadores, $72 \%$ afirmaram que "em parte" (Figura 3A). Além disso, 57\% afirmaram que o estabelecimento de ensino não dispõe de espaço e instrumentos necessários à realização de pesquisas e os demais, 43\%, assinalaram que dispõe "em parte" (Figura 3B). 

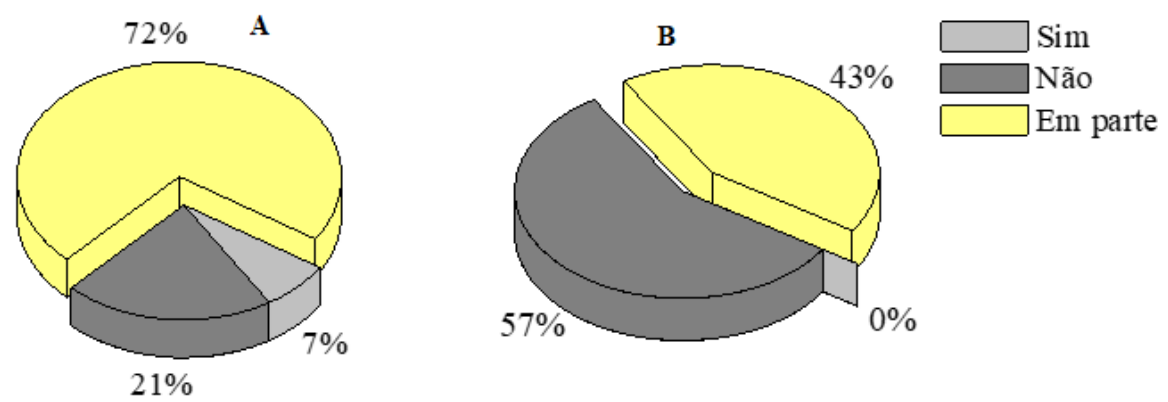

Figura 3. Opinião dos docentes sobre incentivo à pesquisa e a existência de recursos para a sua realização. A: Existência de incentivo da instituição a prática da pesquisa; B: Existência de materiais/instrumentos para a realização de pesquisas.

Ainda, $79 \%$ dos entrevistados alegaram que o instituto apresenta limitações às atividades de investigação, sendo que $42 \%$ apontaram a estrutura física como empecilho para a prática investigativa (Figura 4). De acordo com Fava e Moraes e Fava (2000), a produção científica é fruto de uma tríade: capacitação contínua das pessoas, infraestrutura apropriada e investimento permanente. Castro (1992), citado por Ohira (1998), verificou que a deficiência de recursos materiais $e$ as condições de trabalho foram os maiores obstáculos ao desenvolvimento de pesquisas, conforme o relato dos docentes entrevistados, 0 que, segundo a autora, pode estar relacionado a uma política científica inexplícita na instituição. Já o Fórum de Reflexão Universitária - UNICAMP (2002), acrescenta, citando como exemplo os laboratórios, que tal precariedade deve-se ao crescimento não planejado das instituições, bem como à falta de manutenção adequada e ao grande tempo gasto com a importação de materiais e equipamentos.

Também foi verificado que $34 \%$ dos docentes pesquisados atribuíram a falta de tempo como obstáculo para o desenvolvimento de pesquisas (Figura 4). Consoante à Regulamentação da Carga Horária Docente da instituição, o docente do regimente de 40 horas/Dedicação Exclusiva deve ter, no máximo, 16 horas semanais em sala de aula, devendo as demais horas ser complementadas com atividades de ensino, como planejamento de aulas, atendimento a alunos, participação de reuniões entre outras, e com atividades de pesquisa e extensão (IFAC, 2015).

Para Carvalho e Souza (2014), o regime de dedicação exclusiva oportuniza aos docentes condições para cumprir adequadamente as atividades de ensino, pesquisa e extensão. Ressalta-se, porém, que, provavelmente, o ensino de diferentes disciplinas em diferentes modalidades de cursos, como ocorre na educação profissional, pode interferir na execução de projetos de investigação, uma vez que demandará mais tempo e dedicação para as atividades relativas ao ensino.

Outros docentes relataram como dificuldades a falta de recursos financeiros, falta de capacitação e o fato de que os editais são voltados somente mestres e doutores e disponibilidade do coordenador de pesquisa (Figura 4). 


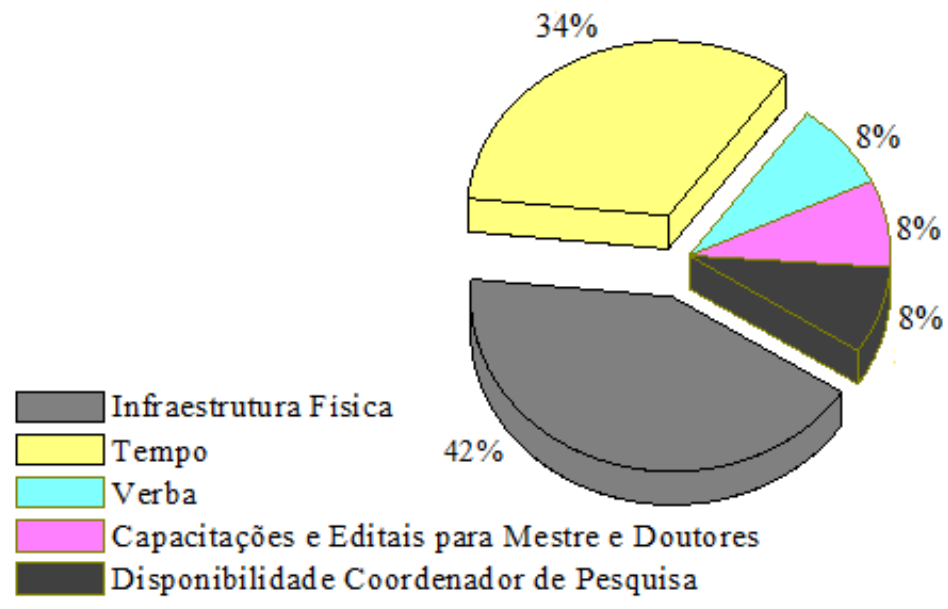

Figura 4. Empecilhos à pesquisa citados pelos professores entrevistados.

Em relação à iniciação cientifica (IC) nos cursos técnicos, a maioria dos entrevistados acredita ser importante. Foi destacado por eles que a IC promove o despertar pela a ciência; melhora a escrita; estimula a curiosidade, o desenvolvimento intelectual e o senso investigativo da realidade; permite conhecer novas possibilidades de se inserir no mundo do trabalho; possibilita formação integral e com mais qualidade; capacita para uma futura vida acadêmica e profissional; oportuniza contato com outros pesquisadores entre outros. Um dos docentes destaca que a

Iniciação científica é fundamental como um incentivo para o discente desenvolver a lógica científica sendo um estímulo à continuidade e a sua contribuição com novas informações científicas que podem contribuir para a região onde vivem. $O$ ingresso na pesquisa pode, além do resultado gerado em relação a conhecimentos, também agregar resultados que vão refletir na formação do aluno (capacidade de raciocínio lógico, organização, ética, responsabilidade, capacidade argumentativa) (ENTREVISTADO 12).

Todos estes apontamentos concordam com as ideias de pesquisadores desta temática, como Fava-de-Moraes e Fava, 2000; Queiroz e Almeida, 2004; Campos et al., 2009; Erdmann et al., 2010, que apesar de serem pesquisas realizadas em Instituições de Ensino Superior, acreditamos que seus resultados também aplicam-se à educação profissional técnica de nível médio.

Um docente expôs que a iniciação científica deve ser direcionada aos alunos dos cursos superiores, alegando que os cursos técnicos devem formar técnicos e não pesquisadores. No entanto, Baracho et al. (2006) e Moura (2007) defendem que a pesquisa deve estar inserida em todos os níveis de ensino e que quanto mais cedo o indivíduo estiver inserido neste contexto, maiores serão os benefícios nos níveis de ensino subsequentes. Destaca-se, que dentre as propostas dos institutos federais está a verticalização do ensino, viabilizando ao egresso do curso técnico o ingresso em curso superior de sua área de formação e, 
posteriormente, na pós-graduação. Logo, a pesquisa, é indispensável nesse processo, e como comentado anteriormente, ela

colabora para edificar a autonomia dos indivíduos, isto é, o desenvolvimento, entre outros aspectos, das capacidades de ao longo da vida de aprender, interpretar, analisar, criticar, refletir, buscar soluções e propor alternativas, potencializadas pela investigação e pela responsabilidade social assumida (MOURA, 2007, p. 23).

Outro entrevistado afirma que a importância da iniciação científica para os cursos técnicos é "total, apesar de difícil, pois os alunos têm uma carga de aula elevada e são imaturos, em sua maioria, para a pesquisa". O elevado número de disciplinas é real nos cursos técnicos integrados ao ensino médio, em que, conforme dados do Registro Escolar da instituição, há uma média de 20 disciplinas ofertadas durante 0 ano letivo. Já nos cursos subsequentes, a quantidade é bastante inferior àquela. Sobre a preocupação do docente em relação ao amadurecimento dos estudantes, Baracho et al., (2006) e Moura (2007) argumentam que as metodologias, objetivos e estratégias de pesquisa devem se adaptar aos seus graus de maturidade intelectual, respeitando o nível de ensino.

Apesar da maioria (93\%) considerar a IC importante nos cursos técnicos, apenas $36 \%$ orientaram alunos nesses programas e, segundo as entrevistas, a baixa adesão aos editais de IC deve-se não só a problemas já citados como estrutura inadequada e falta de tempo, mas também à acomodação e falta de interesse dos docentes, vagas destinadas a mestres e doutores, docentes sem perfil de pesquisador, falta de experiência e capacitação dos professores, edital lançado em época inadequada e falta de apoio, incentivo e/ou divulgação (Figura 5). 

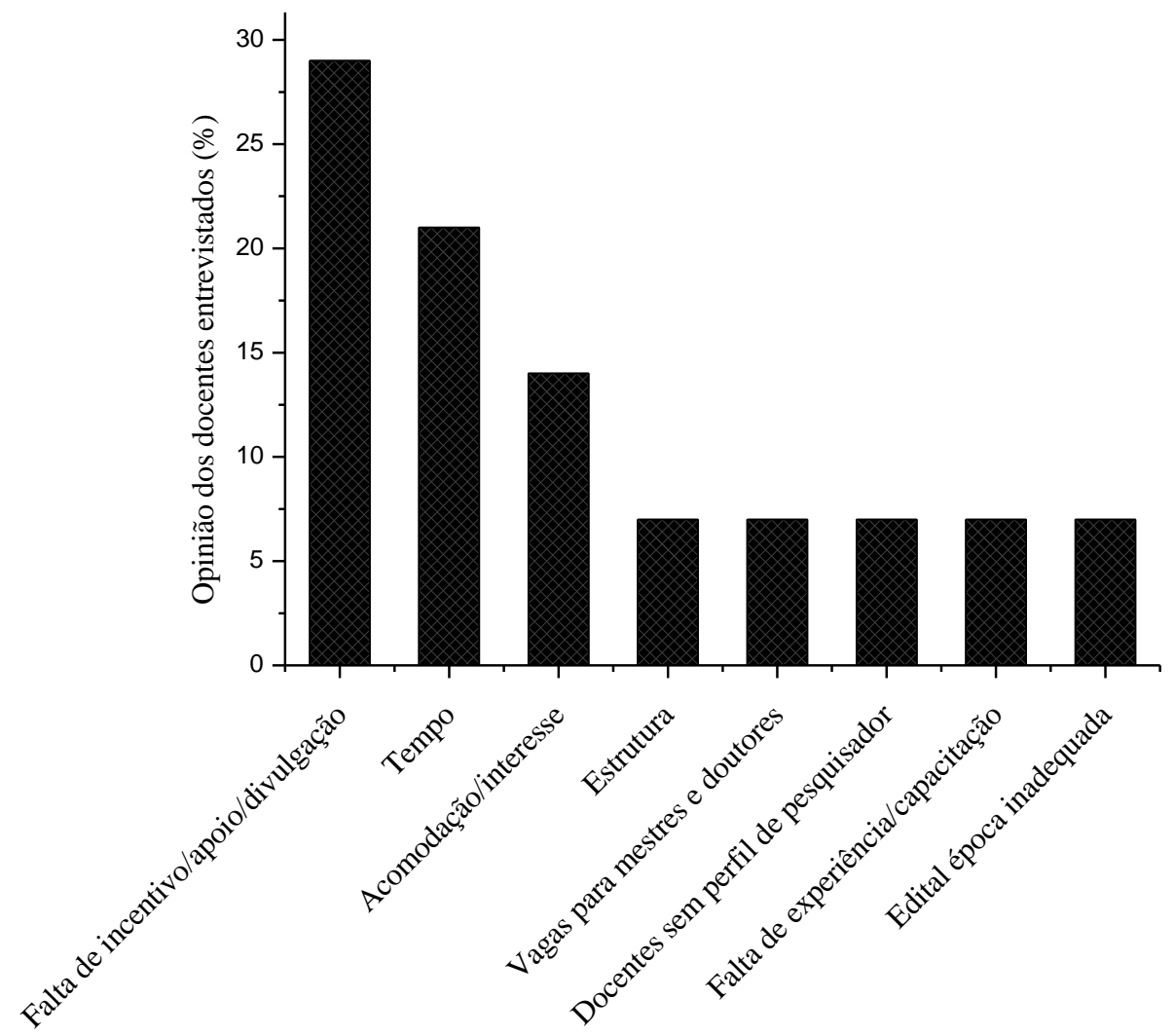

Figura 5. Opinião dos docentes entrevistados sobre os motivos da baixa adesão aos editais de iniciação científica.

A exemplo do trabalho de Leão et al. (2014), as políticas de incentivo à pesquisa em uma instituição têm o poder de alavancar as produções científicas, envolvendo professores e alunos e até mesmo a comunidade externa, daí a importância de incentivar, apoiar e oferecer condições para que os professores, além de lecionar, sejam pesquisadores.

Ainda, os entrevistados citaram algumas ações que a gestão da instituição pode fazer para melhorar e ampliar a pesquisa no campus, a saber, melhoria da infraestrutura e construção/equipamento de laboratórios, realização de cursos de capacitação, explicação mais clara dos editais, oferecimento de mais condições de trabalho ao coordenador de pesquisa, mais incentivo à pesquisa, conscientização dos docentes sobre a importância dessa temática, contratação de docentes para as áreas que estão mais sobrecarregadas de aulas, oferecimento de ajuda de custo ao pesquisador, incentivo à participação de docentes em cursos de pósgraduação, imposição de limite à variação de disciplinas aos professores e promoção de encontros para a troca de informações sobre pesquisa.

Percebe-se, então, que a instituição apresenta, na visão dos docentes, limitações que desfavorecem a realização de pesquisas, não obstante, a maioria reconhece que estas atividades são importantes e que a iniciação científica nos cursos técnicos de nível médio auxilia no desenvolvimento intelectual dos 
estudantes em diversos aspectos. Cabe, dessa forma, à instituição a tarefa de proporcionar boas condições ao trabalho docente, oferecendo infraestrutura adequada, equilibrando a carga horária do professor, criando e ampliando políticas de incentivo à pesquisa entre outros. Evidencia-se, porém, que muitas ações independem da gestão local, já que esta é submetida a instâncias superiores.

\subsection{A INICIAÇÃO CIENTÍFICA NA VISÃO DA EQUIPE GESTORA}

A gestão dos institutos federais é certamente um desafio, pois abrange a oferta de cursos em diferentes níveis e modalidades de ensino e sua associação com a pesquisa e a extensão. Para Escott et al. (2013), a legislação norteia a educação profissional e tecnológica dos institutos federais para as ações de ensino, pesquisa extensão, integrando ciência, tecnologia e cultura como parte essencial à vida humana, bem como o desenvolvimento da capacidade de investigação científica como indispensável para a formação da autonomia intelectual dos estudantes.

Neste sentido, integrantes da gestão do campus foram entrevistados a fim de identificar-se os conceitos, percepções e perspectivas sobre a iniciação científica na instituição. Percebe-se, através dos resultados, que os diretores compreendem a importância da IC para o desenvolvimento do instituto, pois de acordo com eles

Os Instituto Federais nascem com a missão de promoção do ensino técnico e tecnológico que certamente são alavancados através de programas de iniciação científica. Podemos afirmar que tais programas são essenciais para a consolidação dos institutos e para o avanço de tecnologia no Brasil. A importância está na consolidação da inovação científica e no pleno desenvolvimento da sociedade a difusão da ciência (ENTREVISTADO 1)

E além do "ganho com o desenvolvimento intelectual, ainda se extrai as produções oriundas das pesquisas" (ENTREVISTADO 2).

Ainda, semelhante ao que foi perguntado aos docentes, os gestores responderam o porquê da baixa adesão aos editais de iniciação científica no campus, o que, conforme suas respostas, se deu

Pelas especificidades dos editais em razão de serem lançados em período de recesso letivo do campus. O perfil profissional diversificado dos servidores do campus pode ser um elemento colaborador, bem como condições específicas de alguns dos pesquisadores que não tiveram a condição de submeter propostas (ENTREVISTADO 1).

Também foram citadas as limitações dos docentes em escrever projetos de pesquisa, a maior preocupação com ganhos pessoais, a carga horária elevada de alguns docentes e atuação em diferentes turmas e níveis de ensino que exige 
maior dedicação ao ensino. Percebe-se que, ao contrário do que foi citado pela maioria dos docentes entrevistados, a infraestrutura do campus não foi mencionada. No entanto, foi reconhecido que alguns profissionais não dispõem de tempo suficiente para as atividades de pesquisa, o que foi apontado por $21 \%$ dos docentes.

Sobre a infraestrutura da instituição, os gestores afirmaram que estão em diálogo com parlamentares para destinação de emendas ao Campus que possam beneficiar a criação de laboratórios e que estão comprometidos com a reestruturação e adequação dos espaços já existentes e com a aquisição de materiais e equipamentos.

Além disso, os entrevistados citaram seus esforços para incentivar a pesquisa na instituição através da

Divulgação dos editais e disposição do coordenador local para prestar todo o auxílio necessário para os interessados. Houve também oficina da plataforma OCS para submissão de projetos em que todos foram convidados. Além da divulgação dos processos através de e-mail e de reuniões (ENTREVISTADO 1).

Foram citadas ainda a busca de recursos e a disponibilização de bolsas de auxílio à pesquisa e o investimento em parcerias com outras instituições, como a Universidade Federal do Acre (UFAC) e a Empresa Brasileira de Pesquisa Agropecuária (EMBRAPA).

Relacionado aos alunos, os gestores concordam que têm, em parte, a responsabilidade de motivar os discentes a participarem dos programas de iniciação científica e que podem ampliar a divulgação dos editais a este público.

Para auxiliar a gestão do Campus há a Coordenação de Pesquisa e Inovação, cuja função, segundo o Manual de Fluxos e Serviços dos Setores do Campus Cruzeiro do Sul, é orientar e auxiliar os servidores da instituição quanto à elaboração e proposição de projetos de pesquisa, bem como gerir as informações relacionadas a eles. É também característica desta coordenação a intermediação e viabilização da execução das investigações, bem como a divulgação dos resultados e organização e/ou apoio de eventos científicos (IFAC, 2015).

Acredita-se também que a Coordenação de Pesquisa e Inovação, além de garantir o apoio às atividades investigativas, deve motivá-las e promovê-las, pois nas unidades universitárias, "todo o esforço manipulativo em torno da atividade de pesquisa resultará em orientação à formação de uma Política de Pesquisa" (FUJITA, 1998, p. 35), defendendo-se o mesmo para os Institutos Federais.

$\mathrm{Na}$ visão de Fujita (1998), a mediação de informação poderá ser feita através da adoção de um padrão de orientação abrangente com relação a professores e alunos, garantindo o fornecimento de informações precisas, detalhadas e acessíveis, podendo ser propagadas por meio de panfletos, cartazes, exposições orais e contatos pessoais. Para a autora, este esforço é produtivo, pois esclarece, convence, motiva e, acima de tudo, aprimora a formação do graduando. Defendemos o mesmo pensamento para a Educação Profissional. 


\section{CONSIDERAÇÕES FINAIS}

Verifica-se que a Iniciação Científica na vida dos alunos do IFAC/Campus Cruzeiro do Sul é uma atividade que apresenta vantagens, pois além de trabalhar o lado científico dos alunos, desenvolve diversas capacidades e habilidades que enriquecerão sua formação geral. Além disso, os docentes são fundamentais no despertar da vocação científica dos alunos e acreditamos que os orientandos se espelham em seus orientadores e são influenciados por eles. Esta relação pode muito contribuir para a formação científica, ética, moral e social dos discentes.

A pesquisa demonstrou que maioria dos docentes entrevistados acredita que a iniciação científica colabora com a formação investigativa e geral do aluno e compreendem sua necessidade, todavia, poucos a fazem, pois declaram haver empecilhos à pesquisa, dentre os quais, a infraestrutura inadequada, a falta de tempo, a falta de recursos financeiros e de capacitação. Assim, muitas vezes o professor, já com tempo limitado, ao se deparar com a falta de recursos, desestimula-se e deixa de estimular seus estudantes. No entanto, defendemos que as políticas de incentivo e o apoio da instituição têm o poder de transformar realidades como esta.

Assim como os professores devem estimular os alunos, a equipe gestora deve estimular seus docentes. Deve-se criar um ambiente na instituição em que os profissionais sintam a necessidade de contribuir para o desenvolvimento local e regional através da pesquisa para a resolução de problemas existentes.

A equipe gestora acredita que a baixa participação dos docentes nas atividades de iniciação científica tem sido ocasionada, principalmente, por condições específicas dos docentes, sendo reconhecido que alguns têm carga horária elevada e atuam numa diversidade de turmas e níveis de ensino. Ainda, a gestão da instituição confirmou seu compromisso com o desenvolvimento da pesquisa no campus através dos esforços em captar recursos financeiros e em melhorar a infraestrutura.

\section{REFERÊNCIAS}

ALENCASTRE, M. B.; ÉVORA, Y. D. M.; SCOCHI, C. G. S.; SANTOS, B. M. O. Programa institucional de bolsas de iniciação científica - experiência da Escola de Enfermagem de Ribeirão Preto da Universidade de São Paulo. Revista Latino-Americana de Enfermagem, v. 4, n. 2, p. 229-236, julho. 1996.

AMORIM, F. F. Iniciação científica: investindo em novos talentos. Ciência Saúde, v. 22, n. 4, p. 297-400, 2011.

ANTUNES, A.; PEREIRA-JUNIOR, N.; EBOLE, M. F. Gestão em Biotecnologia. $1^{a}$ ed. Rio de Janeiro: E-Papers, 2006, 324p. 
BALLARIN, M. L. G. S.; TOLDRÁ, R. C. A trajetória do pesquisador e da iniciação científica no curso de graduação em Terapia Ocupacional da PUCCampinas. Caderno de Terapia Ocupacional UFSCAR, v. 9, n. 2, p. 67-79, 2001.

BARACHO, M. G.; SILVA, A. F.; MOURA, D. H.; PEREIRA, U.A. Políticas públicas de formação de professores e de financiamento. In: Ensino Médio Integrado à Educação Profissional. Boletim 07, Brasília: MEC, 2006.

BASTOS, F., MARTINS, F.; ALVES, M.; TERRA, M.; LEMOS, C. S. A importância da iniciação científica para os alunos de graduação em Biomedicina. Revista Eletrônica Novo Enfoque, v. 11, n. 11, p. 61-66, 2010.

BRASIL. Lei no 11.892, de 29 de dezembro de 2008. Institui a Rede Federal de Educação Profissional, Científica e Tecnológica, cria os Institutos Federais de Educação, Ciência e Tecnologia, e dá outras providências. D.O.U. Seção 1, de 30 de dezembro de 2008. Brasília, DF, 2008.

BRASIL. Ministério da Educação. Resolução CNE/CEB no 6, de 20 de setembro de 2012. Define as Diretrizes Curriculares Nacionais para a Educação Profissional Técnica de Nível Médio.

BRIDI, J. C. A.; PEREIRA, E. M. A. O impacto da iniciação científica na formação universitária. Olhar do Professor, v. 7, n. 2, p. 77-88, 2004.

BRIDI, J. C. A. Atividade de pesquisa: contribuições da iniciação científica na formação geral do estudante universitário. Olhar de professor, Ponta Grossa, v. 13, n. 2, p. 349-360, 2010.

CAMPOS, F. G. G.; SANTOS, R. F.; SANTOS, F. C. P. A importância da pesquisa científica na formação profissional dos alunos do curso de educação física do UNILESTEMG. Movimentum: Revista Digital de Educação Física, v. 4, n. 2, p. 12-11, 2009.

CARDOSO, G. P.; SILVA-JUNIOR, C. T.; CARVALHO-NETO, A. L. C.; TOUÇA, A. S.; MATTOS, A. C. M. T.; PACHECO, A. B.; BRÍGIDO, D. C.; NACIF, I. Dez anos de iniciação científica: o que aprendemos? Experiência da disciplina de Iniciação Científica no curso de Medicina da UFF. Pulmão RJ, v. 14, n. 2, p. 131-136, 2005.

CARVALHO, O. F.; SOUZA, F. H. M. Formação do docente da educação profissional e tecnológica no Brasil: um diálogo com as faculdades de Educação e o curso de Pedagogia. Educação e Sociedade, v. 35, n. 128, p. 629996, jul.-set. 2014. Disponível em: <http://www.scielo.br/scielo.php?pid=S0101$73302014000300883 \&$ script=sci_arttext>. Acesso em: 15 nov. 2015.

CASTRO, M. H. Produção cientifica dos docentes de Escola Superior de Agricultura Lavras: análise quantitativa. Campinas, 1992. Dissertação (Mestrado em Biblioteconomia) - Departamento de Biblioteconomia, Pontifícia Universidade Católica de Campinas.

CNPq. Anexo V da RN-017/2006. Iniciação Científica Júnior - ICJ. 2006. Disponível em: < http://www.cnpq.br/documents/10157/96bfa431-898f-49b8-a70f4c070af213e6>. Acessado em 18 nov. 2015.

DIRETÓRIO DE GRUPOS DE PESQUISA (DGPB/CNPq). Disponível em: <http://lattes.cnpq.br/>. Acesso em: 05 nov. 2015. 
ERDMANN, A. L.; LEITE, J. L.; NASCIMENTO, C. N.; LANZONI, G. M. M. Vislumbrando o significado da iniciação científica a partir do graduando de enfermagem. Escola Anna Nery Revista de Enfermagem, v. 14, n. 1, p. 26-32, 2010.

ERDMANN, A. L.; PAGLIUCA, L. M. F. Iniciação científica: uma trajetória para a pesquisa. Online Brazilian Journal of Nursing, v. 6, n. 1, 2007.

ESCOTT, C. M.; SOUZA, C. S. S.; HECK, J. X. Desafios da gestão da pesquisa em uma instituição de educação superior pública multicampi no Brasil. In: COLÓQUIO DE GESTÃO UNIVERSITÁRIA DAS AMÉRICAS, 13, 2013. Anais... Florianópolis, UFSC, 2013.

FAVA-DE-MORAES, F.; FAVA, M. A iniciação científica: muitas vantagens e poucos riscos. São Paulo em Perspectiva, v. 14, n. 1; p. 73-7, jan. 2000.

FONSECA, D. M. A pesquisa e a ação pedagógica: o papel dos programas de iniciação científica. Educativa, v. 15, n. 2, p. 287-299, 2012.

FÓRUM DE REFLEXÃO UNIVERSITÁRIA - UNICAMP. Desafios da pesquisa no Brasil: uma contribuição ao debate. São Paulo em Perspectiva, v. 16, n. 4, p. 15-23, 2002.

FUJITA, M. S. P. Gestão do potencial de pesquisa da universidade: proposta de atuação do profissional da informação em Escritórios de Pesquisa na UNESP. Informação e Informação, v.3, n. 2, p. 33-42, 1998.

GIL, A. C. Métodos e técnicas de pesquisa social. 6. Ed. São Paulo: Atlas, 2008.

GOULART, A. T. A importância da pesquisa e da extensão na formação do estudante universitário e no desenvolvimento de sua visão crítica. Horizonte, v. 2, n. 4, p. 60-73, 2004.

HARTMANN, A. M.; ZIMMERMANN, E. Feira de Ciências: a interdisciplinaridade e a contextualização em produções de estudantes de ensino médio. Encontro Nacional de Pesquisa em Educação em Ciência, 7. Anais... Florianópolis, 2009.

IFAC. Resolução no 001/2015 - CONSU/IFAC. Disponível em: $<$ http://www.ifac.edu.br/index.php?option=com_docman\&task=doc_download\&gid= 3533\&ltemid=120 $>$. Acesso em: 18 nov. de 2015.

Manual de Fluxos e Serviços dos Setores de Campus Cruzeiro do Sul - IFAC. Disponível em: $<\mathrm{http}: / / \mathrm{ww} w$.ifac.edu.br/index.php?option=com_docman\&task=doc_download\&gid= 3826\&ltemid=381>. Acessado em 18 nov. $201 \overline{5}$.

2011.

Disponível

em

<http://www .ifac.edu.br/index.php?option=com_content\&view=article\&id=694:ifacrealiza-i-mostra-de-pesquisa-e-inovacao\&catid $=35$ :destaques>. Acesso em: 15 mar. 2016.

LACERDA, A. L.; WEBER, C.; PORTO, M. P.; SILVA, R. A. A importância dos eventos científicos na formação acadêmica: estudantes de Biblioteconomia. Revista ACB: Biblioteconomia em Santa Catarina, v. 13, n. 1, p. 130-144, 2008. 
LEÃO, G. M. C.; JACOMEL, M. C. W.; TAVARES, V. S. O compromisso do IFPR com o ensino profissional tecnológico no Estado do Paraná. Revista Educação e Políticas em Debate, v. 3, n. 1, p. 176-192, 2014.

MACHADO, D. P. et al. Incentivo à pesquisa científica durante a graduação em Ciências Contábeis: um estudo nas universidades do Rio Grande do Sul. Revista de Informação Contábil, Recife, v. 3, n. 2, p. 37-60, abr. 2009.

MARTINS, G. M. M. O que queremos da escola média?A perspectiva de pesquisadores, professores e estudantes de ensino médio. Espacios en Blanco, Serie Indagaciones, v. 22, n. 1, p. 143-164, 2012.

MOCELIN, D. G. Concorrência e aliança entre pesquisadores: reflexões acerca da expansão de grupos de pesquisa dos anos 1990 aos 2000 no Brasil. Revista Portuguesa e Brasileira de Gestão, v.6, n. 11, p. 35-64, 2009.

MOURA, D. H. Educação Básica e Educação Profissional e Tecnológica: dualidade história e perspectivas de integração. Holos, v. 2, n. 23, p. 4-30, 2007.

OHIRA, M. L. B. Por que fazer pesquisa na universidade? Revista ACB: Biblioteconomia em Santa Catarina, v. 3, n. 3, p. 65-76, 1998.

OLIVEIRA, N. A.; ALVES, L. A.; LUZ, M. R. Iniciação científica na graduação: o que diz o estudante de Medicina? Revista Brasileira de Educação Médica, v. 31, n. 3, p. 309-314, 2008.

PALMEIRA, I. P.; RODRIGUEZ, M. B. A investigação científica no curso de Enfermagem: uma análise crítica. Escola Anna Nery Revista Enfermagem, v. 12, n. 1, p. 68-75, 2008.

PEREIRA, L. O.; INOCENTI, A.; SILVA, G. B. A iniciação científica na graduação em Enfermagem na Universidade de São Paulo (1993-1996): análise crítica. Revista Latino-americana de Enfermagem, v. 7, n. 3, p. 77-86, jul. 1999.

QUEIROZ, S. L.; ALMEIDA, M. J. P. M. Do fazer ao compreender ciências: reflexões sobre o aprendizado de alunos de iniciação científica em química. Ciência e Educação, Bauru, v.10, n.1, p.41-53, 2004.

SILVA, C. J. R (org). Institutos Federais lei 11.892, de 29/11/2008: comentários e reflexões. Natal: IFRN, 2009. Disponível em http://portal.mec.gov.br/ setec/arquivos/pdf7/publicações. Acesso em: 01 mar. 2016.

SOUZA, J. M. T.; MARQUES, H. V. C. F. Contribuições da iniciação científica no processo de ensino e aprendizagem em Química. Caderno de Pesquisa, v. 18, n. 3, p. 31-39, 2011.

TENÓRIO, M. P.; BERALDI, G. Iniciação científica no Brasil e nos cursos de medicina. Revista da Associação Médica Brasileira, v. 56, n. 4, p. 375-393, 2010. 